JQME

27,3

Received 7 July 2020 Revised 22 February 2021 16 April 2021

Accepted 30 April 2021

\section{Gone in 2s: a deep dive into perfection analysing the collaborative maintenance pitstop of Formula 1}

\author{
Alberto Martinetti and Preshant Awadhpersad \\ Design, Production and Management Department, University of Twente, \\ Enschede, The Netherlands \\ Sarbjeet Singh \\ Design, Production and Management Department, University of Twente, \\ Enschede, The Netherlands and \\ Maintenance and Operation Division, Luleà University of Technology, \\ Luleä, Sweden, and \\ Leo A.M. van Dongen \\ Design, Production and Management Department, University of Twente, \\ Enschede, The Netherlands
}

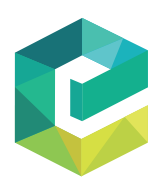

Journal of Quality in Maintenance Engineering Vol. 27 No. 3,2021 pp. 550-564 Emerald Publishing Limited $1355-2511$

DOI 10.1108/JQME-07-2020-0062

\begin{abstract}
Purpose - The paper aims to convert into useable guidelines, the knowledge related to human factors and tasks' organisation, which are embedded in one of the most exciting maintenance actions that are carried out, the pitstop in Formula 1 races.

Design/methodology/approach - The paper opted for a fault tree analysis (FTA) to de-construct all the subtasks and their possible deviations from desirable situations and to evaluate the most relevant information needed for carrying out the pitstop operation. Besides, the SHELL model was applied in a second stage to evaluate the interaction between human being and human interfaces with other components of the system. Once this set of information was crystallised, the research translated it into useable guidelines for organising industrial maintenance actions using the same approach and possible reaching the same results.

Findings - The results of this study is a structured set of guidelines that encompasses the most paramount aspects that should be considered for setting correct maintenance actions. They represent a "guide" for including the different angles that are included during these operations.

Research limitations/implications - The guidelines are potentially applicable to every maintenance operation. The guidelines should be tested on different working domains to check their applicability besides the racing world. Practical implications - This study is a reverse engineering work for creating a scheme to include into maintenance operations aspects such as crew athlete-like fitness, training, technology, organisational issues, safety, ergonomics and psychology.

Originality/value - The value of the paper is deconstructing the results of one of the most successful and prepared maintenance action. The paper takes a different approach in proposing how to structure and create maintenance solutions. The difference in approaches between the maintenance during the pitstop of Formula 1 car and industrial applications enhances the gap that needs still to be filled for further improving maintenance actions out of the racing world.
\end{abstract}

Keywords Maintenance performance, Maintenance optimisation, Maintainability, Human factors, Fault tree analysis

Paper type Research paper

(C) Alberto Martinetti, Preshant Awadhpersad, Sarbjeet Singh and Leo A.M. van Dongen. Published by Emerald Publishing Limited. This article is published under the Creative Commons Attribution (CC BY 4.0) licence. Anyone may reproduce, distribute, translate and create derivative works of this article (for both commercial and non-commercial purposes), subject to full attribution to the original publication and authors. The full terms of this licence may be seen at http:/creativecommons.org/licences/by/4.0/legalcode 


\section{Introduction}

In the world of technological advancements, the need for upgrading industrial practices tends to increase rapidly. As the industries strive to meet the growing market demand, the need for increased uptime and highly reliable machines becomes inevitable. Industrial organisations are continuously seeking new strategies to improve the effectiveness of their operations. Maintenance optimisation and selection of appropriate maintenance strategy play a vital role in the effectiveness of any industrial system's operation (Suzan Alaswad and Xiang, 2017).

In general, maintenance is defined as the combination of all technical and administrative actions, including supervision, which ensures that a system is in the required functioning state (Dekker, 1996). The development of optimal maintenance strategies is necessary for improving system reliability, preventing the occurrence of unexpected system failures and reducing maintenance cost (Kaiser and Gebrael, 2009).

Industry 4.0 and recent technology development enable intelligent and flexible production control using information technology (IT) based on communicating, interacting machines. This advancement in the industry helps to make maintenance decision based on the factual data from the machines. This is achieved by predictive maintenance in recent times. Predictive maintenance is a set of activities that detect the changes in the physical condition of equipment (signs of failure) to carry out the appropriate maintenance work for maximising the service life of equipment without increasing the risk of failure (Wang, 2016).

As the systems become more complex or the stakes become higher, more is expected from systems' availability. In Figure 1, a general overview is given of how the dependence availability of a system requires different aspects of the process to collaborate to reach the required result.

Besides the optimisation and improvement of component reliability, an interesting and relevant aspect to focus on is the impact of human intervention and performance during the maintenance operations, affecting, in the first place, the serviceability and the maintainability, and as a consequence, the actual availability. The information provided by identifying the parameters of availability can be optimised by implementing the probability of human error. Singh et al. (2015) advocated that if the workplace layout, working posture, maintenance manuals and accessibility of tools are poorly planned, maintenance performance can be adversely affected. Moreover, Comberti et al. (2018, 2015a, b) and Baldissone et al. (2019) also demonstrated that human errors still represent a major cause in industrial occupational accidents. Further, in the research conducted by Singh $e t$ al. (2017), it has been observed that time pressure, ability to detect and perceive problems, over-riding information, the need to make decisions and mismatches between the operator and designer's model turn out to be major contributors to human error. Therefore, assessing the "reliability of workers" is of paramount importance (Comberti et al., 2019). One of the most powerful and

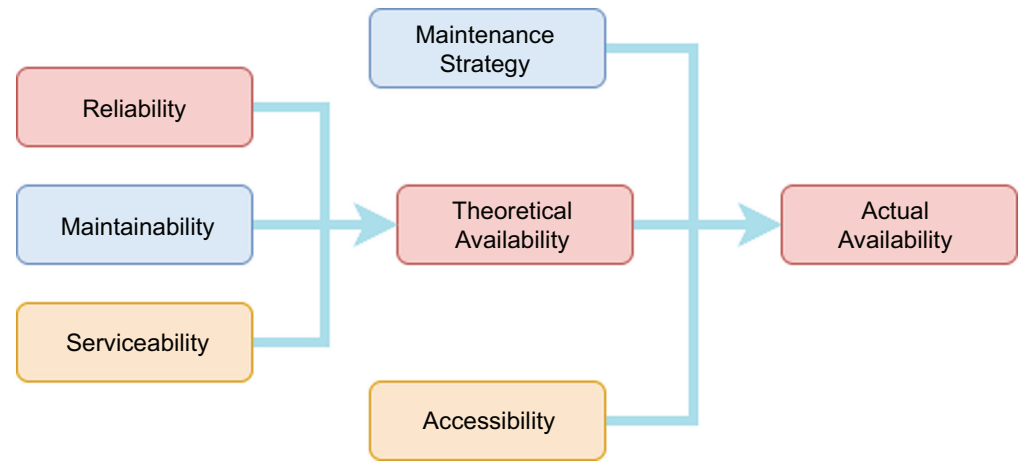

Collaborative maintenance pitstop of Formula 1

Figure 1. Availability dependency from different aspects 
JQME 27,3

well-known technics for tackling this issue is the fault tree analysis (FTA). This analysis offers a complete overview of potential errors and failures caused by the system or/and human errors to identify them beforehand and prepare countermeasures to take the process to near-perfection as possible.

Among all the industrial and non-industrial fields, motorsport is a sector where technology and continuous improvements are the main driven factors. Ever since the first motor racing events in history, the spirit of sporting competitiveness has continuously driven thousands of racing teams, their drivers, managers and engineers to seek perfection, as only the best can stand the challenges and difficulties imposed by this demanding environment. The road to perfection is a philosophy that every participant of the sport has to engrave in the back of his mind to be successful.

Moreover, racing teams aim both to have the fastest asset and to reduce downtime to a minimum. This makes a good maintenance management plan an essential aspect of the job, where high system availability or minimal maintenance time is the primary goal. Consequently, maintenance management and operations become an integral part of any company that prioritises this goal.

Looking at all races and competitions in motorsport, there is one in particular where maintenance operations play such a dominant role: the collaborative maintenance pitstop in Formula 1.

Formula One (Formula 1 or F1) is the topmost race sanctioned by Federation Internationale de l'Automobile (FIA) in the races of single-seater racing cars. In F1 racing, there is a pitstop meant for halting cars for changing tyres, repairing works, refuelling, changing the driver (at the present days, these last two aspects are not present anymore), etc. Pits comprise a pit lane parallel to the track and several garages where this work is carried out. There is a pit crew consisting of 2-20 mechanics for carrying out work in the pit stop. While carrying out the work in pit stop, sometimes there are certain human or technical errors, which may lead to various accidents. Some of these pit stop errors that occurred in past are as follows. During the 1994 German Grand Prix, when the fuel hose was disconnected from the car in the pit, fuel was sprayed out of the nozzle and caught fire (Ten Biggest Pit Fails, 2016). At Argentine Grand Prix 1998, the tyres required for the car and fuel hose were not ready when a car stopped in the pit Bleacher Report (2014). In the 2008 Singapore Grand Prix, an error in traffic lights led to the wrong signal for moving of car with a fuel hose attached. In 2009, Brazilian Grand Prix, lollipop man signalled the driver to leave, but refuelling was not complete, and the fuel hose was ripped off from its mounting trailing behind the car and sprayed the fuel across the pit lane; as a result, another car caught the fire as it drove over it (10 of The Biggest Pit Fails, 2016). In the 2011 Hungarian Grand Prix, it was raining and a huge blue strip of paint was painted on the pit stop, and when a driver tried to stop on the strip of paint, he got slipped and lost control of the car Bleacher Report (2014). In German Grand Prix 2013, the right rear wheel was not properly fit and a signal for leaving the car was given. In Monaco Grand Prix 2016, due to some communication error in the pit stop, the availability of tyres required for the car had been delayed Red Bull to analyse pit stop (2016). At the 2018 Bahrain Grand Prix, due to some sensor errors in the signalling system, an early green light before completion of pit stop resulted in injury to a mechanic. When the car started, the wheel was detached and hit a cameraman (Keith Collantine, 2020). Recently, in December 2020, at Sakhir Grand Prix in Bahrain, due to some problems with the Radios of one F1 team and misunderstanding among the workers, a wrong pair of tyre was fitted into a car (Keith Collantine, 2020). This is the ideal example to analyse how the various aspects are already included in their near-perfect maintenance pitstop. It also offers a powerful ground for reflections on an important technical aspect such as the management of change, considered at the same time both a useful tool to improve the availability of a system, but also a source of issues in terms of safety if not properly managed (Demichela et al., 2017). 


\section{The research problem and the methodology}

Formula 1 pitstop is based on one of the most complete and optimised maintenance plans created. Formula 1 industry has worked to perfect their processes for years to complete the pitstop maintenance sequence without errors and in a blink of the eye. Formula 1 pitstop represents an excellent case study extrapolating the base knowledge and for implementing interesting aspects for different (and less quick in maintenance operations) sectors. Researching this aspect to develop a set of universal and useable guidelines in any industry will give a significant contribution to maintenance optimisation.

The paper opted for a qualitative FTA to de-construct all the sub-tasks and their possible deviations from desirable situations and to evaluate the most relevant information needed for carrying out the pitstop operation. Once this set of information was crystallised, the research translated it into universal knowledge for organising industrial maintenance actions.

\section{Formula 1 pitstop: the analysis}

The desire to keep downtime as low as possible and reliability high stimulate us to look for ways to perfect our existing processes. Formula 1 world seems to be a leading example of this trend.

Formula 1 racing can be classified as global motorsport; with the fame and global status also comes the high pressure to perform. Many aspects lead to a successful race/championship. It all starts from the design of the car to the last action performed by the driver at the race after the race is finished. Apart from a global sport, Formula 1 is also a business, which means that the goal is to make a profit whilst keeping the performances at the highest level. Cost-effectiveness and efficiency become important parameters in the whole process. This aspect is noticeable in every stage of the project, and it is especially reflected in collaborative maintenance operations such as the pitstop. Motivation and competitiveness need to be there as the performance aspect correlates to the commercial aspect (Jenkins, 2020). It is during this stage that the maintenance crew comes together to perform one of the most perfect choreographed maintenance sequences created and has to be executed almost perfectly as any second lost during the pitstop can have negative consequences on the drivers' performance and placing.

However, this organisation efficiency has not been always there. The progress the pitstop has made over the years is outstanding. Comparing the pitstop times over the past 30 years, it is notable that they vary tremendously. This contributed to the fact that 1982 was the first time an F1 car came into the pitstop area for new tyres and refuelling. In 1984, the refuelling practice was banned again; it was reintroduced from 1994-2009. During this era, the pitstop was dependent on how fast the car could be refuelled, in 2008, the FIA set the max flow rate of fuel into the tank of no more than $12.1 \mathrm{~L}$ per second (FIA, 2008). After 2010, the teams started focusing on the pitstop times and fluent sequence of the tire change again as refuelling was finally banned once again to reduce the cost and environmental impacts of this sport. From that moment till current days, steady progress can be observed with teams now regularly breaking the $2 \mathrm{~s}$ barrier for a standard pitstop with the record now set at $1.82 \mathrm{~s}$.

The progress can be attributed to the years of practice and skill honing, gathering data, identifying mistakes and potential design flaws and fixing them throughout the years.

The design of the car has made some significant changes throughout the years, as new technological advances changed the way the car was designed and constructed. The FIA added strict regulations for competitors and crew members to ensure the races could take place in a safe manner and environment. The design of the car also had to be to the minimum required standards set by the FIA. The FIA, thus, set a required minimum standard for the complete race starting from the design of the car all the way to specify the requirements of the safety wear that maintenance crew members have to wear and minimum performance of the equipment used. The competitors were required to adjust and improve the required

Collaborative maintenance pitstop of Formula 1 
JQME

27,3

\section{4}

aspects. This resulted in race cars being built with optimal maintainability, serviceability and accessibility. Only then could the competitor hope to have the edge over the competition.

In the following paragraph, a more detailed analysis will be done of the pitstop organisation, analysing tasks, corresponding actions, crew training and safety protocols. This detailed view will offer a better understanding of how the crew manages to carry on one of the most complicated and high-stake maintenance sequences near-perfection repetitively.

The pitstop will be analysed identifying tasks and failures related to the pitstop and the required crew. A complete representation of the pitstop can be found in Figure 2.

Around 34 tasks need to be completed during a pitstop.

\subsection{Pit crew}

The pit crew does not have a specific person assigned to a specific job. The crew usually consists of the team's mechanics who also assist during the race as the pit crew. Every team member is

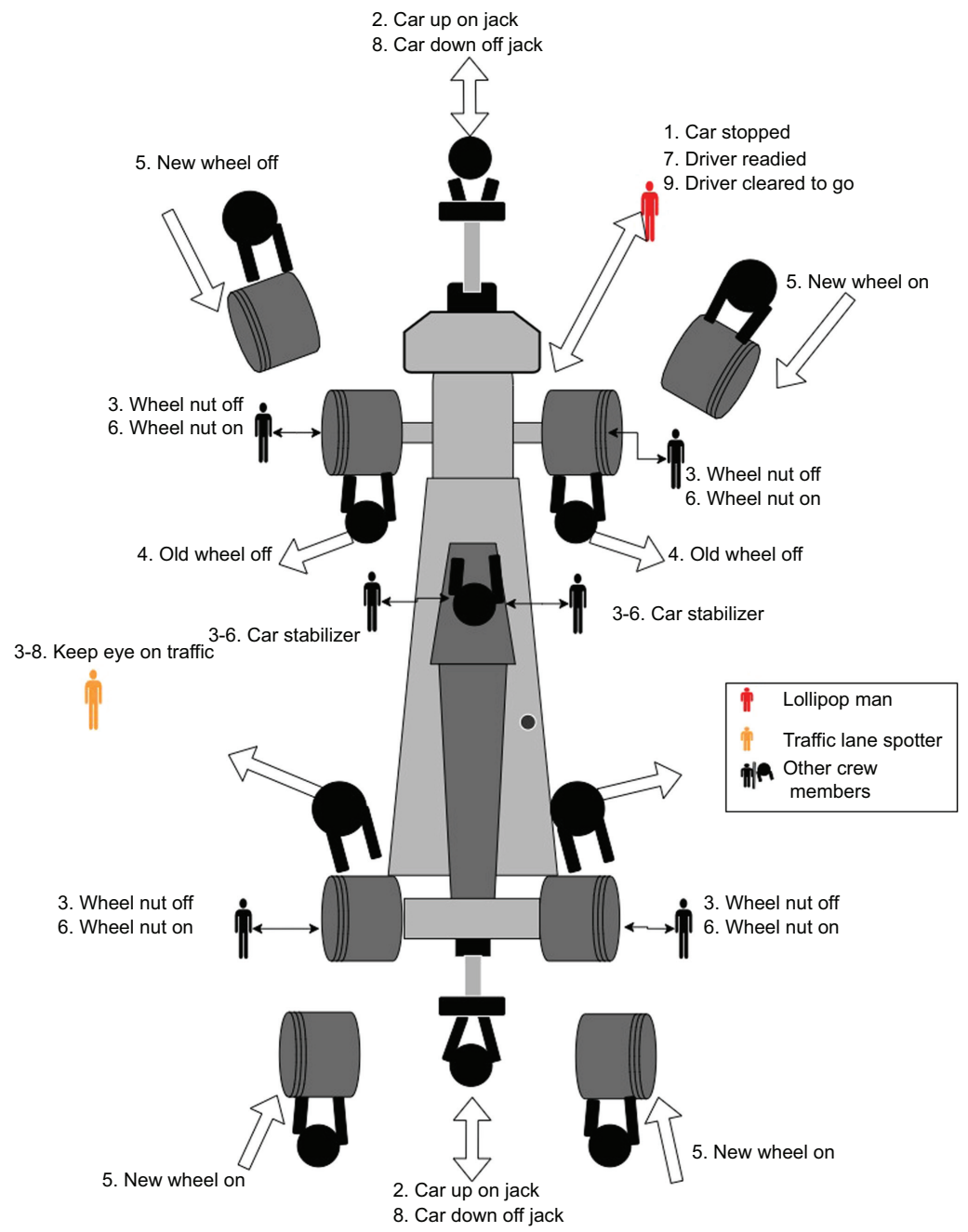

Figure 2.

Formula 1 pitstop representation 
equipped and trained to do every task, to be interchangeable. However, the most common approach of the teams is to assign a mechanic to always the same task. Tasks are usually assigned based on physical capabilities as all members have their characteristics. The crew consists of a minimum of 18 to a maximum of 22 mechanics. Table 1 summarises their function.

The FIA does not have any restrictions on the number of crew members, so every team is free to assign additional crew members with additional tasks, e.g. adjusting the front flap or carrying the tyre warmers.

\subsection{Pit equipment}

As said, the crew have to execute 34 specific tasks normally in less than $3 \mathrm{~s}$. This requires the crew to have specific equipment designed for efficiency and effectiveness, ensuring the crew is comfortable handling them, but keeping the high performance at the same time. A list of equipment and its specific use is presented in Table 2. Because of the high stakes, failing
Collaborative maintenance pitstop of Formula 1

\begin{tabular}{|c|c|c|}
\hline Crew member & Quantity & Function \\
\hline $\begin{array}{l}\text { Lollipop man/traffic } \\
\text { lane spotter }\end{array}$ & 1 & $\begin{array}{l}\text { This task was usually assigned to the chief mechanic or most experienced } \\
\text { member of the crew. His/her tasks encompass overseeing all sub-tasks of the } \\
\text { pitstop and making sure they are executed correctly and in an orderly } \\
\text { fashion. Moreover, he/she gives the go/no-go sign for the driver to come in } \\
\text { and leave the pit area. This mechanic's task has been recently substituted by } \\
\text { a red/green light device, but still operated by one mechanic (traffic lane } \\
\text { spotter) }\end{array}$ \\
\hline Jackman & 4 & $\begin{array}{l}\text { Crew members responsible to lift and down the car, using a manual jack } \\
\text { positioned at the front and back and using in the side-middle part of the car. } \\
\text { They have to simultaneously lift the car approximately } 10 \mathrm{~cm} \text { of the ground, } \\
\text { so the tyres can be switched with minimal resistance, but the lifting up and } \\
\text { downtime are minimised. There are always two spare jackmen in stand-by } \\
\text { close to the operating ones }\end{array}$ \\
\hline Gunman & 4 & $\begin{array}{l}\text { During the tyre change, four gunmen are stationed at the four tyres to loosen } \\
\text { and tighten the wheel nut of the tyres in one fluent movement. The moment } \\
\text { the car comes to almost a full stop, the gun and wheel nut need to have made a } \\
\text { connection to change the tyres as fast as possible }\end{array}$ \\
\hline Tyres exchangers & 8 & $\begin{array}{l}\text { During the pitstop, a group of } 4 \text { people are in charge of taking the old tyres off } \\
\text { and } 4 \text { others are in charge of putting on the new ones }\end{array}$ \\
\hline Wingman & 3 & $\begin{array}{l}\text { Crew members responsible for front and rear wings adjustment or } \\
\text { replacement }\end{array}$ \\
\hline Car's stabiliser & 2 & $\begin{array}{l}\text { Crew members who support and balance the lift of the car for facilitating the } \\
\text { wheels' exchange }\end{array}$ \\
\hline
\end{tabular}

Table 1. List of the crew members operating during a pitstop

\begin{tabular}{lcl}
\hline Equipment & Quantity & Function \\
\hline Pneumatic gun & 8 & $\begin{array}{l}\text { An air gun that sends pulses of torque to the bolt to tighten/loosen the wheel } \\
\text { nut. The device has a lightning system indicating when a procedure is } \\
\text { finished. Gunmen also raise their hands when finished so that electronic } \\
\text { failure can be avoided }\end{array}$ \\
$\begin{array}{l}\text { Wheel nut } \\
\text { Quick-release jack }\end{array}$ & 4 & $\begin{array}{l}\text { A modified version of a car jack that has a quick-release button to save time } \\
\text { The jackman in front uses a swivel jack so that he can move out of the way } \\
\text { quickly }\end{array}$ \\
$\begin{array}{l}\text { An automated light signalling system indicates when the crew is done and } \\
\text { the driver can leave. The crew's equipment is connected to it } \\
\text { Special electrical blankets are used to warm up the tyres to increase traction } \\
\text { and stability on the track }\end{array}$ & 1 & 1
\end{tabular}

Table 2.

Equipment, materials and specific functions 
JQME 27,3

556 equipment cannot be accepted. Gunmen always have a spare pneumatic gun available and backup mechanics with quick-release, and swivel jacks are standing close to the car.

Due to the hazardous environment, the crew operates during the race, all crew members wear safety gears and safety equipment (e.g. heat-resisting gloves, kneepads, elbow pads and fire-resisting gear).

\subsection{Pitstop tasks}

The duration of an average Formula 1 pitstop is less than $3 \mathrm{~s}$. This gives the crew little room for error. The maintenance protocols are frequently practised starting from the crew picking up the tyres to two cars coming in right after each other. This ensures that the crew knows the routines well with every aspect and scenario rehearsed. This paragraph will give further specification regarding the common maintenance tasks that have to be performed by the crew during the race.

The sequence and the description of the tasks are summarised in Table 3:

This entire sequence has to be executed perfectly by a minimum of 18 crew members for the pitstop to yield any advantage in/during the race.

\begin{tabular}{|c|c|c|}
\hline Task & Description & Crew member \\
\hline Pitstop preparation & $\begin{array}{l}4 \text { tyre changers have to quickly run and get the required tyres, } \\
\text { the crew walks in predetermined paths, no interference is met } \\
\text { whilst transporting the tyres and wrap them in electrical } \\
\text { heating sheets }\end{array}$ & All crew members \\
\hline Car positioning & $\begin{array}{l}\text { As the car pulls in, the front jackman and the } 4 \text { gunmen stand } \\
\text { in position. The car is guided into place by laser pointers to } \\
\text { indicate the ideal position for the driver to stop the car. As the } \\
\text { car comes in, the front jackman already stands in front of the } \\
\text { oncoming race car. This is also regarded as the most } \\
\text { dangerous position of the crew as the driver can misjudge the } \\
\text { position or the breaking speed }\end{array}$ & $\begin{array}{l}\text { Driver and front } \\
\text { jackman }\end{array}$ \\
\hline \multirow[t]{2}{*}{ Car's lift } & $\begin{array}{l}\text { The rear and front jackman lift the car, simultaneously the } 4 \\
\text { gunmen detach the } 4 \text { lug nuts and } 4 \text { tyre changers unwrap the } \\
\text { heated tyres and stand into position }\end{array}$ & $\begin{array}{l}\text { Front and rear } \\
\text { jackmen }\end{array}$ \\
\hline & $\begin{array}{l}\text { The } 2 \text { stabilisers crew members help to lift and balance the car } \\
\text { on both sides }\end{array}$ & $\begin{array}{l}\text { Car's stabiliser crew } \\
\text { members }\end{array}$ \\
\hline Wheel nut removal & The 4 gunmen remove the wheel nuts with the pneumatic gun & Gunmen \\
\hline $\begin{array}{l}\text { Old wheelset } \\
\text { removal }\end{array}$ & $\begin{array}{l}4 \text { crew members (tyre changers) simultaneously remove the } \\
\text { old tyres and move to the back }\end{array}$ & Tyre exchangers \\
\hline $\begin{array}{l}\text { New wheelset } \\
\text { placement }\end{array}$ & $\begin{array}{l}\text { The } 4 \text { other tyre changers quickly step into the position with } \\
\text { the new tyres and place them on the car }\end{array}$ & Tyre exchangers \\
\hline $\begin{array}{l}\text { Wheel nut } \\
\text { placement }\end{array}$ & $\begin{array}{l}\text { The } 4 \text { gunmen attach the lug nuts keeping the tyres in their } \\
\text { place }\end{array}$ & Gunmen \\
\hline Car's lowering & $\begin{array}{l}\text { Simultaneously to the previous task, the jackmen lower the } \\
\text { car and step away }\end{array}$ & $\begin{array}{l}\text { Front and rear } \\
\text { jackmen }\end{array}$ \\
\hline Greenlight for & The lollipop man (or traffic lane spotter) who has been & Lollipop man/traffic \\
\hline leaving the pit & $\begin{array}{l}\text { keeping an eye on everything gives the all-clear as the traffic } \\
\text { light system gives the driver the signal he can go }\end{array}$ & lane spotter \\
\hline \multicolumn{3}{|c|}{ Additional tasks (simultaneously to wheel nut removal and wheel nut placement) } \\
\hline Wings' adjustment & $\begin{array}{l}2 \text { front and } 1 \text { wingmen adjust front and rear wings to the } \\
\text { preferred position and step out of position }\end{array}$ & Wingmen \\
\hline $\begin{array}{l}\text { Helmet's windshield } \\
\text { cleaning }\end{array}$ & A crew member cleans the windshield & Crew member \\
\hline
\end{tabular}

Table 3.

List of pitstop tasks 
3.4 Pitstop fault tree analysis

FTA was developed in the early 1960s at the Bell Telephone Laboratories to perform safety analysis (Dhillon and Singh, 1981). It is broadly used to perform reliability analysis of engineering systems and is a logical representation of the relationship of fault events that may cause an adverse event, called the top event, to occur. The events that result in the occurrence of the top event are connected and generated by logic gates AND and OR. The OR gate provides a true output (i.e. fault) when one or more of its inputs are true (fault). In this study, FTA was used to perform a complete system breakdown of all the requirements to give a better indication of how all independent factors/influences put together to form a coherent and intertwined process.

Amongst the possible techniques available to identify failures, the power of the FTA is to use deductive logic to understand all the underlying causes of a particular failure in a sufficiently complex system so that the likelihood of failure can be reduced through improved system design. Contrary to an Failure Mode, Effect and Criticality Analysis (FMECA), which is a bottom-up analysis technique, an FTA takes a top-down approach to assess failure consequences. An FTA can be applied to analyse the combined effects of simultaneous, noncritical events on the top event, to evaluate system reliability, to identify potential design defects and safety hazards, to simplify maintenance and troubleshooting, to identify root causes during a root cause failure analysis, to logically eliminate causes for an observed failure. These mentioned features represent the essential tools for investigating the possible technical, human and organisational issues of the pitstop (Kritzinger, 2016).

By implementing an FTA, the possible unexpected situations can be identified in an F1 pitstop (Figure 3, Table 4):

(1) Technical issue;

(2) Driver error;

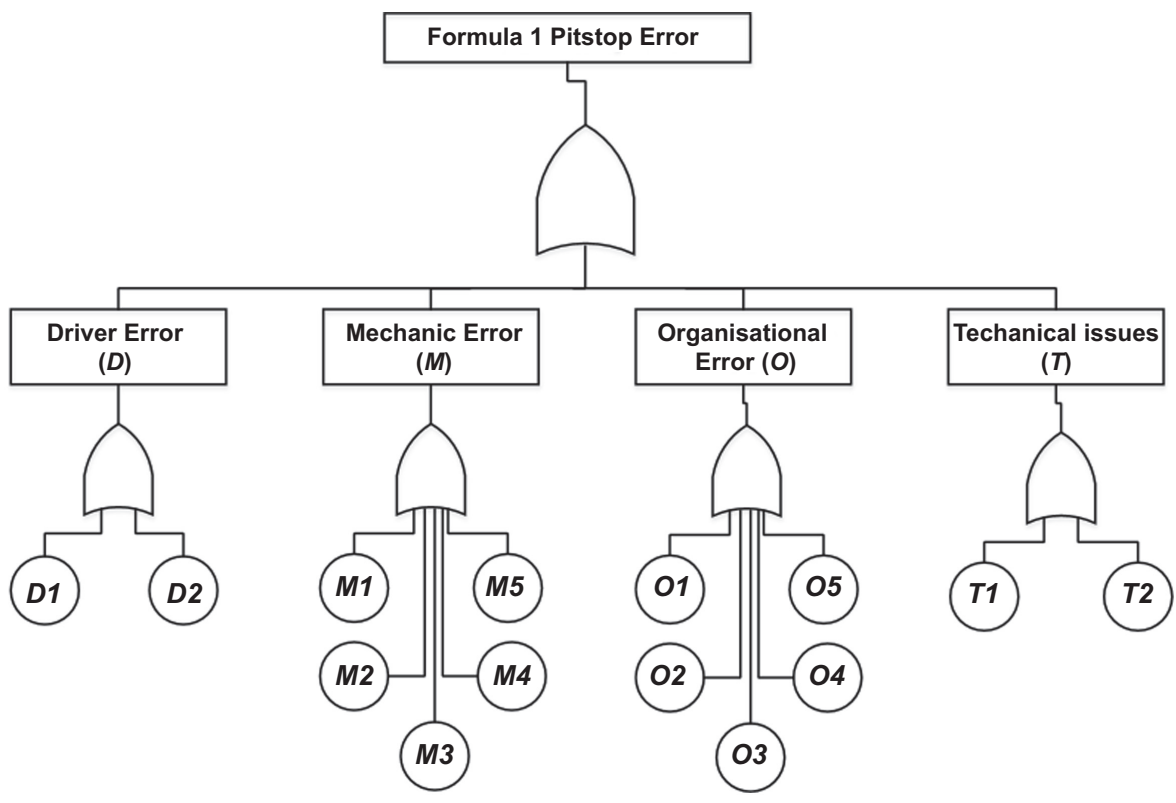

Collaborative maintenance pitstop of Formula 1 


\begin{tabular}{|c|c|c|}
\hline $\begin{array}{l}\text { JQME } \\
27,3\end{array}$ & $\begin{array}{l}\text { Driver error (D) } \\
D 1 \\
D 2\end{array}$ & $\begin{array}{l}\text { Hitting a mechanic (jackman) misjudging speed and distance } \\
\text { Stopping the car in a sub-optimal position }\end{array}$ \\
\hline 558 & $\begin{array}{l}\text { Mechanic error (M) } \\
\text { M1 } \\
\text { M2 } \\
M 3 \\
\text { M4 } \\
\text { M5 }\end{array}$ & $\begin{array}{l}\text { The slow movement in putting the wheel off (wheelman) } \\
\text { The slow movement in putting the wheel on (wheelman) } \\
\text { The slow movement in removing the wheel nut } \\
\text { The slow movement in putting the wheel nut } \\
\text { The slow movement in replacing the front wing }\end{array}$ \\
\hline & $\begin{array}{l}\text { Organisational error }(O) \\
\text { O1 } \\
\text { O2 } \\
\text { O3 } \\
\text { O4 } \\
\text { O5 }\end{array}$ & $\begin{array}{l}\text { Unprepared for changing the tyres } \\
\text { Prepared with wrong tyres } \\
\text { Unprepared for replacing the front wing } \\
\text { Unsafe release of car in the pit lane } \\
\text { Unsafe release of the car with unlocked tyres }\end{array}$ \\
\hline $\begin{array}{l}\text { Table } 4 \text {. } \\
\text { Minimal cut set } \\
\text { produced by the FTA }\end{array}$ & $\begin{array}{l}\text { Technical issue (T) } \\
T 1 \\
T 2\end{array}$ & $\begin{array}{l}\text { Pneumatic guns not working } \\
\text { Jack not working }\end{array}$ \\
\hline
\end{tabular}

(3) Pit crew error; and

(4) Organisational error.

To assess the points mentioned above, the following steps were taken:

(1) Problems/failures are precisely defined and the setting in terms of system goals are derived. Tasks and failures are precisely defined, and the derivations caused by a human error from the system goals are identified.

(2) All tasks, data, equipment, actions, protocols and needed interfaces are identified for the operators so that the system goals can be achieved.

(3) All possible human errors, which can affect the performance/result, are identified and solutions/preventive measurements are presented.

(4) The proposed protocols and procedures to prevent human errors are modelled.

(5) Possible errors are screened.

(6) The remaining errors are quantified and recovery probabilities are compared to define the likelihood of success.

(7) The optimised protocol is tested against the system goals and performance to make sure the system functions accordingly.

(8) All monitorable necessary parameters need to be documented so that the system can be monitored and improved over time.

The pitstops' efficiency and success rely on a near-perfect entanglement of the environment, hardware, pit crew and preparation (training, rehearsals and logistics).

To assess the team's performance, all these aspects have to be taken into consideration. By using the SHELL model, redeveloped by Frank Hawkins to assess the human factor in Flight (Hawkins, 1987), this task can be performed. The SHELL model adopts a systems perspective that suggests the human is rarely, if ever, the sole cause of an accident. The systems perspective considers a variety of contextual and task-related factors that interact with the 
human operator within a system to affect operator performance (Wiegmann and Shappell, 2003). As a result, the SHELL model considers both active and latent failures in the system.

The method uses four main factors in conformity with the design:

(1) Liveware (L), is the humans who work on the process (pit crew);

(2) Hardware $(\mathrm{H})$, the equipment, instruments used during the process (equipment and gear of the team);

(3) Software (S), the regulations, rules and protocols to follow; and

(4) Environment, the surroundings that may influence the process.

How this integrates and works for the betterment of the process can be seen in Figure 4.

The four SHELL factors can be seen as sub-models of a process that influence each other. The performance drop in one subsystem may have consequences for the other. To further show how mismanagement for the SHELL subsystems have on the Liveware, further analysis is done and the influence of each subsystem is elaborated in regards to the Liveware (L) subsystem.

3.4.1 Connection between human and SHELL model elements. The pit crew can be identified as the Liveware (L) of the pitstop. They are responsible for performing maintenance during the race. The importance of training, techniques used during the pitstop, mental training and experience gained during rehearsals are to be attributed to the Software element (S). The use of various equipment like a pneumatic gun, wheel nut, quickrelease jack, swivel jack, pitstop light, electric tyre warmers, gloves and other safety equipment are classified as Hardware $(\mathrm{H})$. The pitlane is a noisy and busy environment, with many teams competing, cars and crew are making their way simultaneously. This makes it a difficult place to concentrate on. This may also affect the performance of each crew member, which in all will affect the crew's performance and influence the procedures, thus harming the pitstop time.

The entanglement between the subsystems shows that each of them has to be optimised for the process to be optimal. The effect of the Liveware (pit crew) can be optimised by creating the best possible foundation for them to work from; this can be done by optimising the other subsystems as they can be managed prerace. To fully optimise the Liveware, the crew is also handpicked, going through various mental, physical and educational tests to be considered for the job. Thus, the recruitment protocols and applicant selection are also optimised and specialised for the function.

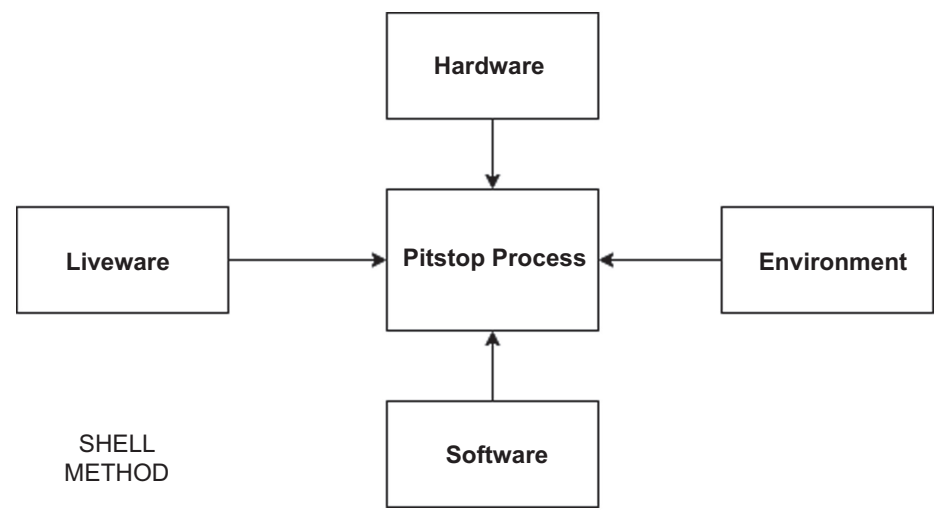

Collaborative maintenance pitstop of Formula 1
Figure 4. Integration for the betterment of a maintenance process 
JQME 27,3

\section{0}

\section{From F1 pitstop to other industrial sectors: the maintenance guidelines}

From the previous analysis, the following points emerged.

They can be divided into technological and organisational and human factors (Table 5).

The development of the current pitstop sequence has been a process of years of data collection and changing the regulations accordingly. The FIA issues reports indicating the minimum standards all competitors need to follow to complete. This not only ensures a definite standard of competitions but enforces the competitors to design the cars in a specific way, keeping safety and efficiency as a priority.

Using the concepts designed and implemented by the FIA over the years as a blueprint, the following guideline concept can be proposed:

(1) Guidelines improving the process;

(2) Guidelines ensuring human capability; and

(3) Guidelines for improving organisational reliability.

The proposed guidelines need to be integrated to effectively improve the entire system and improve reliability or increase the success rate of the operation.

\subsection{Guidelines improving the process}

The success of an operation or process starts with its design. The design has to be optimised for the process to work as effectively or efficient as possible. The following steps can be implemented universally and to optimise the process prioritising the success rate.

(1) Define the process/project and the associated tasks completely. The more detailed the description is, the more insight it presents on different possible scenarios;

(2) Identify possible failures or mishaps endangering the process/project;

(3) Propose possible solutions for failures or undesired situations;

(4) Identify the cost/time needed to implement the solutions;

(5) Calculate the recovery time needed from the failure/ set back;

(6) Redefine the process/project with the identified shortcomings and recoveries; and

(7) Determine the success rate; if not satisfied, identify the most critical shortcomings and implement design changes.

\subsection{Guidelines ensuring human capability}

The success of every process is dependent on the person executing the required steps. Human errors can lead to major setbacks or losses. The following steps are proposed to improve human reliability, thus increasing the probability that the set goal can be reached:

(1) Train the personnel in the tasks required to perform;

\begin{tabular}{ll}
\hline Technological and organisational & Human factors \\
\hline Pitstop equipment & The physical and mental health of the crew members \\
Risk assessment and management & Psychology \\
Ergonomics of the pitstop task & Competitive drive \\
Resilience towards unexpected events & Crew training routines \\
Predetermined standing/working space & Crew practice routines \\
\hline
\end{tabular}

Table 5.

Technical, organisational and human factors requirements 
(2) Create an all-around worker; let the personnel be familiar with all tasks associated with his/her work environment. This ensures that the personnel will be able to better judge situations and calculate the appropriate action when put under stress;

(3) Rehearse potential unwanted situations and the corresponding recovery trajectory. This will improve the reaction time needed when an actual unwanted situation arises (Kendall et al., 2005);

(4) Ensure that the personnel are happy and motivated. Enhancing the work climate will make the personnel perform the tasks better and with more focus (Snow et al., 2002);

Collaborative maintenance pitstop of Formula 1

(5) Promote a health-conscious lifestyle; personnel who are in good health and physical condition have better diets and perform better as there is a direct correlation between diets and performance (Kapur et al., 2019).

\subsection{Guidelines improving organisational reliability}

A process/project can be improved by optimising the organisational aspect of the project. If every process or aspect is beforehand identified and defined, a higher success rate can be reached. The following steps are proposed to optimise the organisational aspect.

(1) Determine the needed equipment/services needed to perform the identified tasks/ processes;

(2) Identify the optimal placement of equipment or the ideal time to rent the required services;

(3) When critical equipment is used always have a backup; and

(4) Apply double-check systems where important processes/tasks are checked and confirmed by different methods to ensure process success.

The implementation of the proposed guidelines helps to improve the efficiency and success of the project/system. Important is to note that a feedback loop needs to be implemented in all parts of the set of guidelines. As historical data and system success rate are obtained, the processes and tasks within the project/system can be improved accordingly. As new technology and theories are discovered and implemented, the entire process can be improved, ensuring a certain reliability and success rate.

Ergonomics also play a role in employees' overall performance and improving the working climate and reducing the hazard of muscle-skeleton diseases. Therefore, correct equipment and accessories design, such as seat design, equipment comfort, need to be addressed to improve and fasten manual material handling. Finally, psychological effects like cumulative trauma disorders have to be tackled to improve productivity and improve the overall well-being of the worker (Fernandez , 1995). Ergonomics can be seen as an essential philosophy to take people into account when we design or organise (Wilson and Sharples, 2015).

By implementing the set of proposed guidelines and mentioned aspects, a competitive and healthy work environment can be created, ensuring high motivation levels.

The guidelines improve on the fundamentals of maintainability, serviceability and accessibility. This helps improve the overall availability and creates the foundation to maximise human reliability implementation effects.

\section{Discussion}

By using the FTA method, the pitstop event was analysed. This approach helped to order and to de-construct the main maintenance operation in all the sub-tasks and their possible 
JQME 27,3

deviations from desirable situations and to evaluate the most relevant information needed for carrying out the pitstop operation.

The deconstruction of the tasks underlined how human reliability is a key factor for the success of the project. The pit crew were directly involved with the high-stake race and had a direct influence on the outcome of the race. Promoting FTA and improving human reliability become important aspects of the process. Formula 1 industry made a specific effort to not only provide their personnel with the best equipment suited for the job and training in their specific job but rather creating a work culture that focuses on excellence, training every team member in all required tasks and obligations. This ensures that if a specific team member is not able to be present, the rest of the group is qualified to ensure the continuity of the process. Moreover, rehearsal of everyday tasks/hazardous situations makes the reaction time and individual assessment during these events better, thus improving human reliability.

The set of guidelines wants to act as a reference to achieve overall success in maintenance operations considering human capability as a central aspect. Ensuring a work culture where team members can depend on one another improves the overall performance of the team, fostering a well-practised sequence of all the actions to achieve near-perfection. To promote a cohesive unit behaviour, the process/project needs to be optimised, and the objective needs to be clearly stated. Personnel needs to be continuously trained, and equipment needs to be continuously developed for fastening the maintenance process.

\section{Conclusion and further research}

The paper focused on developing a set of universal guidelines to be implemented in any process/project to optimise maintenance operations. By using Formula 1 pitstop as a case study, the guidelines were derived and proposed. An in-depth analysis of the pitstop maintenance sequence indicated that human capability and reliability are some of the biggest factors contributing to its success. The analysis of the approach used by Formula 1 teams to maximise the success rate of the maintenance sequence indicates that the team functions as one cohesive unit where mistakes made by a team member have a strong impact on the success of the process. However, even if human errors or equipment malfunctions occur, a well-rehearsed recovery plan ensures the team can still function within any situation. Furthermore, continuous practice and implementation of new maintenance techniques contribute to developing a specific work culture that focuses on eliminating failures and mishaps, striving for excellence and perfection.

All the implied methods and steps found in Formula 1 pitstop maintenance create the set of proposed guidelines. The implementation of a feedback loop ensures that processes can be adjusted and redefined accordingly, ensuring the team has the perfect foundation set to maximise their effort and improve their reliability. By developing a competitive yet healthy work environment, high motivation can be generated, and various improvement points can easily be identified and corrected.

As said, the study focuses on providing a set of guidelines to improve an already existing maintenance process, ensuring a higher success rate. The guidelines give clear suggestions in which way the process should be optimised and the set goal/ target can be achieved also. Finally, the guidelines improve the fundamentals of maintainability aspects from a human perspective, helping in improving overall availability and in creating the foundation to maximise FTA implementation effects.

\section{References}

Alaswad, S. and Xiang, Y. (2017), "A review on condition-based maintenance optimisation models for the stochastically deteriorating system", Reliability Engineering and System Safety, Vol. 157(C), pp. 54-63. 
Baldissone, G., Comberti, L., Bosca, S. and Murè, S. (2019), "The analysis and management of unsafe acts and unsafe conditions. Data collection and analysis", Safety Science, Vol. 119, pp. 240-251, doi: 10.1016/j.ssci.2018.10.006.

Bleacher Report (2014), Pit stops gone wrong: 10 famous gaffes in the pit lane", available at: https:// bleacherreport.com/articles/2004800-pit-stops-gone-wrong-famous-gaffes-in-the-pit-lane (accessed 30 December 2020).

Comberti, L., Baldissone, G. and Demichela, M. (2015a), "Workplace accidents analysis with a coupled clustering methods: S.O.M. and K-means algorithms", Chemical Engineering Transactions, Vol. 43, pp. 1261-1266, doi: 10.3303/CET1543211.

Comberti, L., Baldissone, G., Bosca, S., Demichela, M., Murè, S., Petruni, A., Djapan, M. and Cencetti, S. (2015b), "Comparison of two methodologies for occupational accidents pre-cursors data collection, safety and reliability of complex engineered systems", Proceedings of the 25th European Safety and Reliability Conference, ESREL 2015, pp. 3237-3244, doi: 10.1201/ b19094-426.

Comberti, L., Demichela, M., Baldissone, G., Fois, G. and Luzzi, R. (2018), "Large occupational accidents data analysis with a coupled unsupervised algorithm: the S.O.M. $k$-means method. An application to the wood industry”, Safety, Vol. 4 No. 4, doi: 10.3390/safety4040051.

Comberti, L., Leva, M.C., Demichela, M., Desideri, S., Baldissone, G. and Modaffari, F. (2019), "An empirical approach to workload and human capability assessment in a manufacturing plant", in Longo, L. and Leva, M., (Eds), Human Mental Workload: Models and Applications. H-WORKLOAD 2018. Communications in Computer and Information Science, Vol. 1012, Springer, Cham. doi: 10.1007/978-3-030-14273-5_11.

Dekker, R. (1996), "Applications of maintenance optimization models: a review and analysis", Reliability Engineering and System Safety, Elsevier Science, pp. 229-240.

Demichela, M., Baldissone, G. and Camuncoli, G. (2017), "Risk-based decision making for the management of change in process plants: benefits of integrating probabilistic and phenomenological analysis", Industrial and Engineering Chemistry Research, Vol. 56 No. 50, pp. 14873-14887, doi: 10.1021/acs.iecr.7b03059.

Dhillon, B.S. and Singh, C. (1981), Engineering Reliability: New Techniques and Applications, John Wiley and Sons, New York.

Fernandez, J.E. (1995), "Ergonomics in the workplace", Facilities, Vol. 13 No. 4, pp. 20-27, doi: 10.1108/ 02632779510083359 .

Federation Internationale de l'Automobile-FIA (2008), "Formula one technical regulations", available at: http://argent.fia.com/web/fia-public.nsf/115F0A1E47E0A282C12573FB0042CB0D/\$FILE/12008\%20F1\%20TECHNICAL \%20REGULATIONS\%2022-02-2008.pdf (accessed 22 June 2020).

Kaiser, K.A. and Gebrael, N. (2009), "Predictive maintenance management using sensor-based degradation models", IEEE Transactions on Systems Man and Cybernetics - Part A Systems and Humans, Vol. 39 No. 4, pp. 840-849, doi: 10.1109/TSMCA.2009.2016429.

Hawkins, F.H. (1987), Human Factors in Flight, 2nd ed., Ashgate, Aldershot.

Jerkins, M. (2020), "Performance at the limit", available at: https:/www.cambridge.org/core/books/ performance-at-the-limit/1664AD1E7F3F52EECCCEA57C582392D2 (accessed 16 June 2020).

Kapur, S., Debar, V. and Kaur, R. (2019), "Lifestyle affects the pre-competitive state anxiety: study on male and female basketball players", International Journal of Physiology, Nutrition and Physical Education, Vol. 4 No. 1, pp. 1079-1082.

Keith, C. (2020), "Russell's race-losing tyre mix-up was not due to human error", available at: https:// www.racefans.net/2020/12/06/russells-race-losing-tyre-mix-up-was-not-due-to-human-errorwolff/ (accessed 30 December 2020).

Kendall, K., Kendall, J. and Lee, K. (2005), "Understanding disaster recovery planning through a theatre metaphor: rehearsing for a show that might never open", Communications of the Association for Information Systems, Vol. 16, doi: 10.17705/1CAIS.01651.

Collaborative maintenance pitstop of Formula 1 
JQME 27,3

Kritzinger, D. (2016), "Fault tree analysis", Aircraft System Safety: Assessments for Initial Airworthiness Certification, pp. 59-99, ISBN: 978-0-08-100889-8.

Red Bull to analyse pit stop error (2016), available at: https:/f1i.com/news/57440-red-bull-analyse-pitstop-error-cost-ricciardo.html (accessed 30 December 2020).

Singh, S., Kumar, R. and Kumar, U. (2015), “Applying Human factor analysis tools to a railway brake and wheel maintenance facility", International Journal of Quality in Maintenance Engineering, Vol. 21 No. 1, pp. 89-99.

Singh, S., Arnab, M. and Miltos, K. (2017), "Incorporating human reliability analysis to enhance maintenance audits: the case of Rail Bogie maintenance", International Journal of Prognostics and Health Management, Vol. 8, pp. 1-10, ISSN 2153-2648, E-ISSN 2153-2648 (article id 062).

Snow, J.L. (2002), "DNSc, RN enhancing work climate to improve performance and retain valued employees", The Journal of Nursing Administration, Vol. 32 Nos 7/8, pp. 393-397.

Ten Biggest Pit Fails (2016), available at: https://www.carthrottle.com/post/10-of-the-biggest-pit-failsin-formula-1-history/ (accessed 30 December 2020).

Wang, K. (2016), "Intelligent predictive maintenance system- industry 4.0 scenario", WIT Transactions on Engineering Sciences, WIT Press, Vol. 113, pp. 1-10, doi: 10.2495/ IWAMA150301, ISSN 1743-3533.

Wiegmann, D.A. and Shappell, S.A. (2003), A Human Error Approach to Aviation Accident Analysis: The Human Factors Analysis and Classification System, Routledge, London.

Wilson, J.R. and Sharples, S. (2015), Evaluation of Human Work, 4th ed., CRC Press, Boca Raton FL.

\section{Further reading}

Ferrari pit stop error (2018), available at: https:/www.formula1.com/en/latest/article.ferrari-explainpit-stop-error-that-led-to-mechanic-injury.3DC0fk181aWyuiOi4eSKEg.html (accessed 30 December 2020).

Federation Internationale de l'Automobile-FIA (2020), "2021 F1 regulations", available at: https:// www.fia.com/2021-f1-regulations (accessed 22 June 2020).

\section{Corresponding author}

Alberto Martinetti can be contacted at: a.martinetti@utwente.nl

For instructions on how to order reprints of this article, please visit our website:

www.emeraldgrouppublishing.com/licensing/reprints.htm

Or contact us for further details: permissions@emeraldinsight.com 